María Marta Mariconde*, Adriana Incatasciato **

\title{
Uso de tecnologías emergentes en la enseñanza de la realidad urbana FAUD UNC Córdoba, Argentina ${ }^{1}$
}

\author{
Cómo citar: \\ Mariconde, M. \& Incatasciato, A. (2020). Uso de las tecnologías emergentes en la enseñanza de la realidad
} urbana FAUD UNC Córdoba. Designia 7(2), 167-175.

${ }^{1}$ Proyecto de Investigación con subsidio de la Secretaría de Ciencia y Técnica de la Universidad Nacional de Córdoba - Argentina.

* Arquitecta, egresada de la Facultad de Arquitectura, Urbanismo y Diseño de la Universidad Nacional de Córdoba, Argentina, 1992. Profesora adjunta en la cátedra Morfología III: Morfología Urbana y Profesora Asistente en la cátedra Teoría y Métodos B, ambas de la Carrera de Arquitectura de la FAUD UNC. Investigadora directora de Proyecto de Investigación con Subsidio de la Secretaría de Ciencia y Técnica de la UNC. Miembro del Instituto del Color FAUD UNC y del Grupo Argentino del Color. E-mail: mmmconde@gmail.com ORCID: https://orcid.org/0000-0002-0253-2890

** Arquitecta, egresada de la Facultad de Arquitectura de la Universidad Católica de Córdoba, 1979. Profesora adjunta con dedicación semiexclusiva en la cátedra Morfología III: Morfología Urbana, de la carrera de Arquitectura de la Facultad de Arquitectura, Urbanismo y Diseño de la Universidad Nacional de Córdoba, Argentina. Investigadora Asesora académica de Proyecto de Investigación con Subsidio de la Secretaría de Ciencia y Técnica de la UNC. Miembro del Instituto del Color FAUD UNC y miembro del Grupo Argentino del Color.

E-mail: adrincat@gmail.com ORCID: https://orcid.org/0000-0002-6908-8552
Palabras clave:

Tecnologías emergentes, aprendizaje móvil, enseñanza superior, color urbano.

\section{Key words:}

Emerging technologies, mobile learning, university education, urban color.
Recibido: 28/03/2019

Aceptado: :04/07/2018 


\section{Resumen:}

En la sección Disertaciones sobre Diseño del Vol 7, №1 de la revista Designia, las autoras invitadas presentan un artículo corto de reflexión, en el que se exponen prácticas pedagógicas con tecnologías emergentes en la asignatura de Morfología III: Morfología Urbana, de la FAUD Universidad Nacional de Córdoba, Argentina.

El taller experimental toma como objeto de estudio al sector del Mercado Norte de la ciudad de Córdoba y allí propone el desarrollo de lecturas de ciudad, enfocadas en el análisis del color urbano, bajo la aplicación didáctica de herramientas tecnológicas como dispositivos y aplicaciones móviles e internet.

La metodología propuesta incluye el desarrollo de un mapeo digital colaborativo del sector, un relevamiento del color digital percibido y la conceptualización de los resultados a partir de un video de síntesis.

La experiencia, arroja resultados que permiten visualizar las ventajas de la tendencia educativa del aprendizaje móvil y el uso de los recursos tecnológicos. Se considera que el ejercicio motiva y dinamiza los procesos de enseñanza y aprendizaje y fomenta la construcción colaborativa del conocimiento.

\section{Abstract:}

In the section "Dissertations on Design" of Vol 7, No. 1 of Designia magazine, the invited authors present a short article of reflection, in which pedagogical practices with emerging technologies are exposed in the subject of Morphology III: Urban Morphology, of the FAUD National University of Córdoba, Argentina.

The experimental workshop takes as an object of study the North Market sector of the city of Córdoba and there proposes the development of city readings, focused on the analysis of urban color, under the didactic application of technological tools such as devices, mobile applications and internet. 
The proposed methodology includes the development of a collaborative digital mapping of the sector, a relief of the perceived digital color and the conceptualization of the results from a synthesis video.

The experience results allow us to visualize the advantages of the educational trend of mobile learning and the use of technological resources. It is considered that the exercise motivates and stimulates the teaching and learning processes and promotes the collaborative construction of knowledge.

\section{Introducción}

El importante incremento de las innovaciones tecnológicas y de su apropiación por parte de las personas, hace que expresiones como web $2.0 \mathrm{o}$ web social se consideren hoy parte del pasado, donde el enfático aumento de los indicadores de conexión y uso, consecuencia de la convergencia de celulares inteligentes y tabletas digitales, internet, redes de alta velocidad en movilidad y redes sociales, nos cambia la vida.

El concepto de hiperconectividad constituye un elemento clave del análisis de lo que está ocurriendo en el entorno de las TIC y su impacto en lo económico, social y concretamente en lo educativo, ámbito sobre el que nos interesa reflexionar, y que implica los planteamientos ligados al aprendizaje con tecnología y a su aplicación didáctica pedagógica.

Por ello, como docentes investigadoras de la Arquitectura y el Diseño, es importante apuntar al desarrollo de las posibilidades que ofrecen las tecnologías emergentes (Adell y Castañeda, 2012) en la enseñanza del diseño arquitectónico y urbano, donde, al decir de George Veletsianos (2010), aquellas aparecen como "herramientas, conceptos, innovaciones y avances utilizados en diversos contextos educativos al servicio de diversos propósitos relacionados con la educación" (p. 3), englobando tanto las herramientas, como las ideas sobre su uso. Esto permite la construcción de aprendizajes basados en la observación, la apropiación y la investigación de la realidad de la arquitectura y la ciudad, mediante dispositivos tecnológicos móviles, desde la noción de mobile learning o aprendizaje móvil.

Este concepto involucra una metodología para la enseñanza y el aprendizaje que abarca todo tipo de dispositivos portátiles, tales como teléfonos inteligentes, tabletas y todo aparato de mano que tenga alguna forma de conectividad inalámbrica. Se marca entonces la evolución desde una educación pasiva hacia lo que se denomina, según Dolors Reig (2013), "aprendizaje aumentado" (p.150), centrándose en el aprendizaje autónomo de los estudiantes favorecidos por la web y sus alcances, y por la posibilidad de estar conectados en forma permanente a la inteligencia colectiva mediante estas unidades móviles. 
En este nuevo contexto de hiperconectividad, la relación entre educación y TIC avanza sobre los planteamientos ligados al aprendizaje con tecnología y a la aplicación didáctica y pedagógica. Por ello, se hace necesario reflexionar sobre la educación en un medio en el que la ubicuidad de la tecnología traspasa todos los ámbitos de la vida de los estudiantes, donde los celulares inteligentes, tabletas, videos, redes sociales y aplicaciones digitales, constituyen su cotidianidad, convirtiéndose en espacios vitales que los vinculan a la comunidad.

Los dispositivos móviles posibilitan el acceso permanente al mundo digital, en cualquier lugar, en cualquier momento $\mathrm{y}$, de cualquier forma. $\mathrm{Su}$ fin es el de localizar, mapear, acceder a servicios e información, navegación, publicidad y promoción, de arte o juegos, enriqueciendo la experiencia de los lugares.

Esta ubicuidad del aprendizaje a través de la web posibilita múltiples contextos, diversas puertas de entrada al conocimiento, la colaboración, la participación, la creatividad, la interacción, la conversación, favoreciendo la inteligencia colectiva y la construcción social del conocimiento.
Dispositivos móviles en la realidad urbana: lecturas de ciudad

La asignatura Morfología III: Morfología Urbana, de la FAUD Universidad Nacional de Córdoba, Argentina, aborda la enseñanza de la ciudad desde su forma, considerando como objeto de estudio un sector concreto de la ciudad de Córdoba. Como docentes e investigadoras de la FAUD UNC, y desde el Taller Experimental de la Forma Urbana, los contenidos temáticos del proyecto de investigación "Prácticas pedagógicas con tecnologías emergentes. Aplicación de herramientas digitales en la enseñanza de la realidad arquitectónica y urbana", se aplicaron a prácticas en clases de taller de la mencionada asignatura.

En este marco, durante la visita al sector de estudio con estudiantes y docentes, se propuso como experiencia didáctica concretar "lecturas de ciudad", utilizando tecnologías emergentes y promoviendo el aprendizaje móvil como modo alternativo de lectura, registro y comunicación en el reconocimiento de la ciudad, con recursos tecnológicos que la mayoría de los estudiantes poseen.

Esta experiencia didáctica innovadora en las clases de Arquitectura, promueve el conocimiento en movimiento y genera, en la visita al sector de estudio, una dinámica en su lectura y reconocimiento al utilizar recursos tecnológicos para obtener mejores rendimientos y motivaciones. De esta forma, el proceso educativo es más vivencial, más real, lo que influye de manera directa en el interés del estudiante, que ve afectada su rutina de trabajo cotidiano presencial.

El modo alternativo de lectura, registro y comunicación en el reconocimiento de la ciudad aporta otras percepciones sobre el espacio urbano. Dentro del 
Laboratorio Taller, a cargo de docentes integrantes de la investigación, se desarrollan experiencias prácticas enmarcadas en distintos contenidos del programa de la asignatura. Se exponen a continuación las prácticas trabajadas por estudiantes pertenecientes a cuatro talleres de la asignatura en el sector del Mercado Norte, ciudad de Córdoba, Argentina.

\section{Mapeo digital colaborativo - Lectura de la realidad.}

En instancias de lectura de la situación urbana a intervenir, y como primera tarea práctica del año, se propuso generar un mapeo digital colaborativo entre el docente y los estudiantes. Esta herramienta posibilitó compartir la información y los datos obtenidos de la realidad del sector, en función del relevamiento geométrico, perceptual y vivencial que los estudiantes desarrollan en la etapa de lectura e interpretación de la forma urbana, desde el programa de la asignatura.

La mecánica operativa consistió en la visita al sector del Mercado Norte para, mediante el uso de dispositivos móviles, recabar información in situ acerca del espacio urbano. En el mismo momento, con acceso a conectividad inalámbrica en sus aparatos, los estudiantes obtenían la posibilidad de ingresar en el sitio web del mapa colaborativo Meipi Lecturas digitales Mercado Norte, a partir del escaneo de código QR proporcionado en la guía del trabajo práctico correspondiente. Allí, de manera colaborativa y participativa, en grupos, los estudiantes geoposicionaron sus imágenes, textos, apreciaciones del sector, construyendo un mapa de miradas de la realidad urbana.

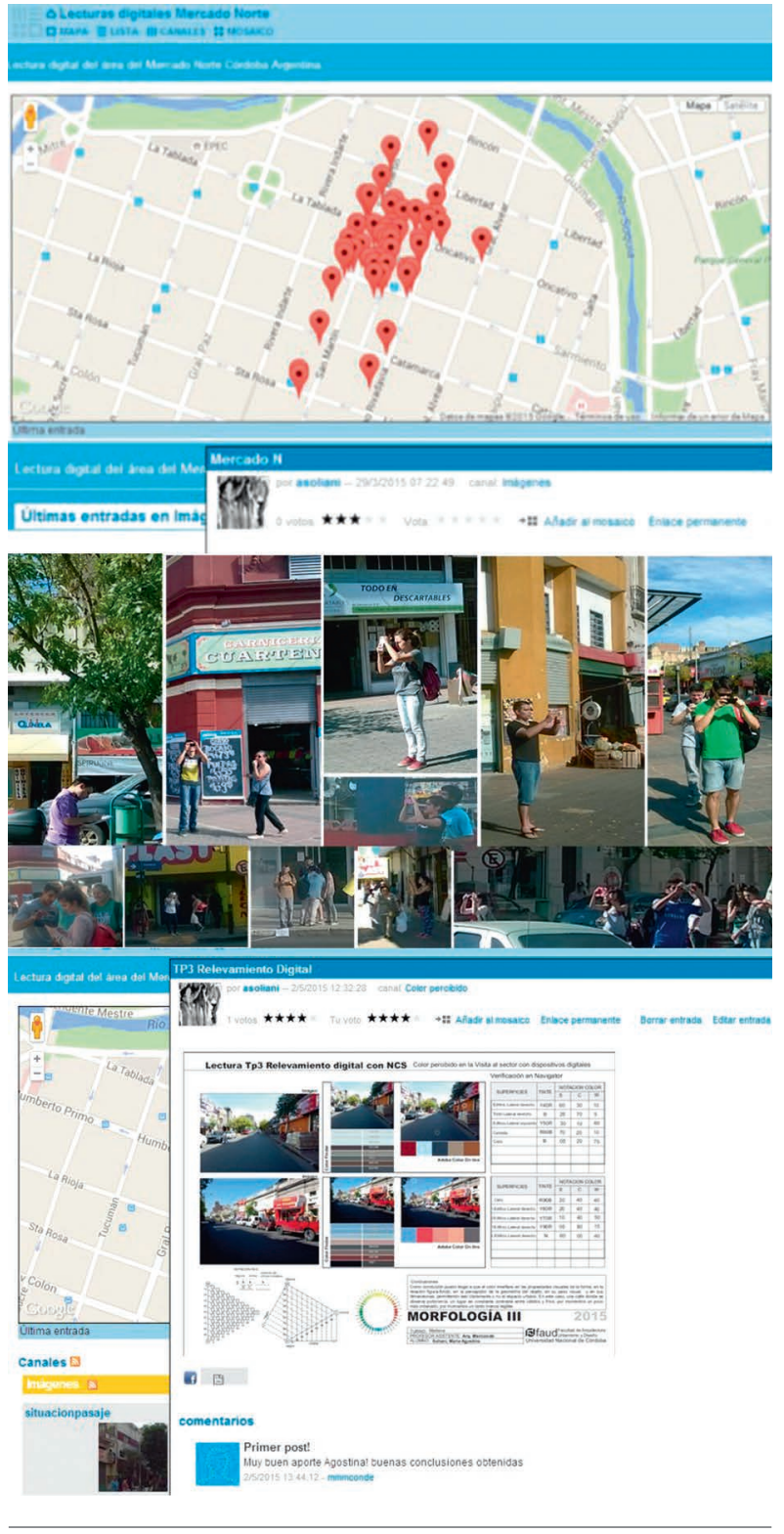

Figuras 1 y 2. Geolocalización en la Web. Mapeo Digital colaborativo Meipi. Fuente: autoras. 


\section{Relevamiento digital NCS Color percibido - Lectura de color.}

La intención en esta práctica fue transferir a una nueva dimensión procesos de aprendizaje de color urbano que habitualmente se desarrollan en taller, avanzando así con el aprendizaje móvil en el levantamiento cromático.

Para esto, se concretó una nueva visita al Mercado Norte y se realizó, en grupos de 2 o 3 alumnos, el registro fotográfico con teléfonos celulares inteligentes y tabletas con posibilidades de conexión inalámbrica a internet. El procesamiento de lo registrado fue inmediato a través de las aplicaciones gratuitas de lectura cromática previamente descargadas en los dispositivos, tales como Adobe Color, Color Finder y Real Colors, elegidos según el sistema operativo de cada dispositivo. Así, de manera sincrónica, se detectaron y seleccionaron colores, y se definieron paletas cromáticas de los enfoques obtenidos. Esta actividad también integró el mapa digital colaborativo, al solicitar su transferencia en una ficha síntesis y su posterior posteo en el Meipi. Así, se compartieron lecturas cromáticas del sector y variados aportes a la percepción cromática del espacio urbano.

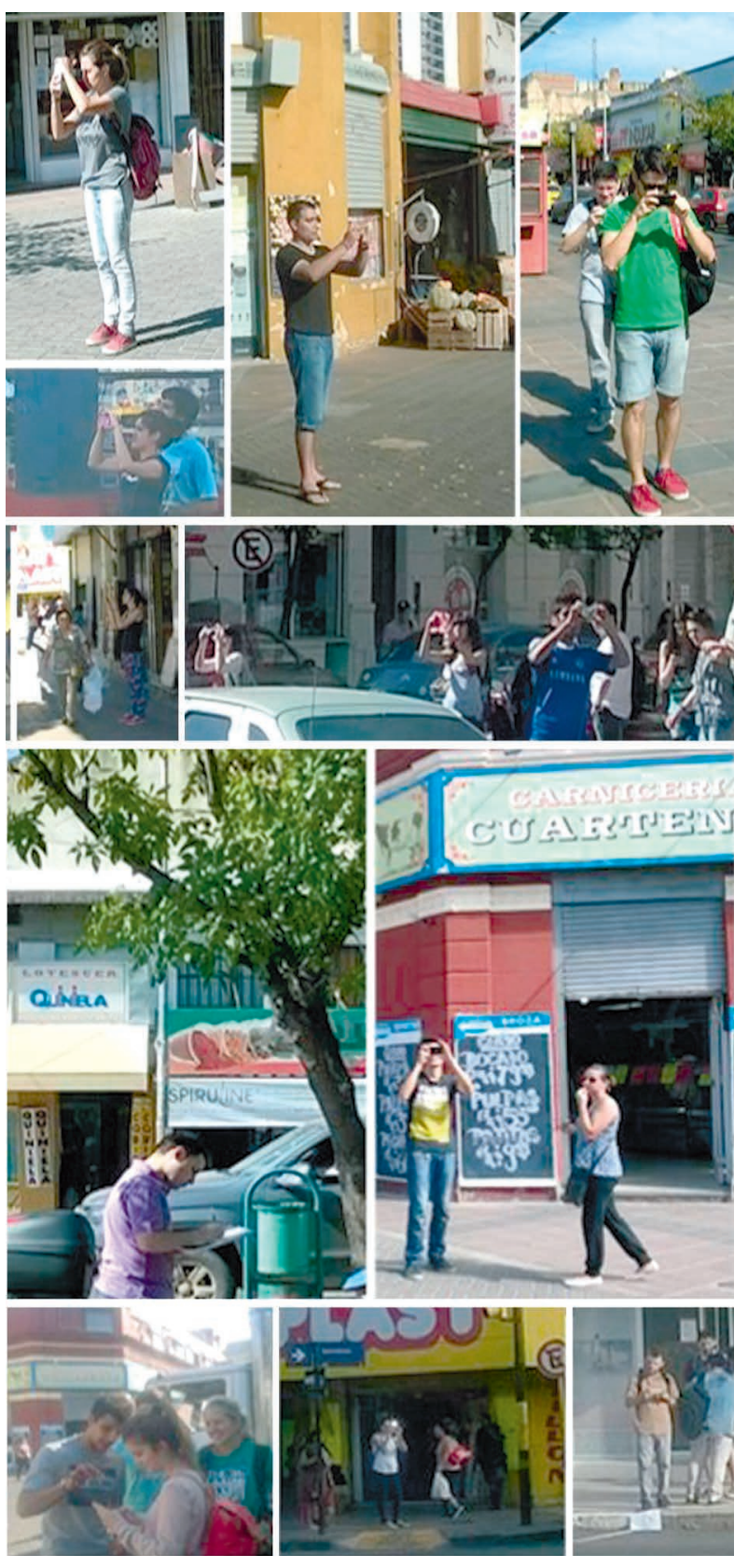

Figura 3. Relevamiento cromático con aplicaciones digitales. Aprendizaje móvil. Fuente: autoras. 

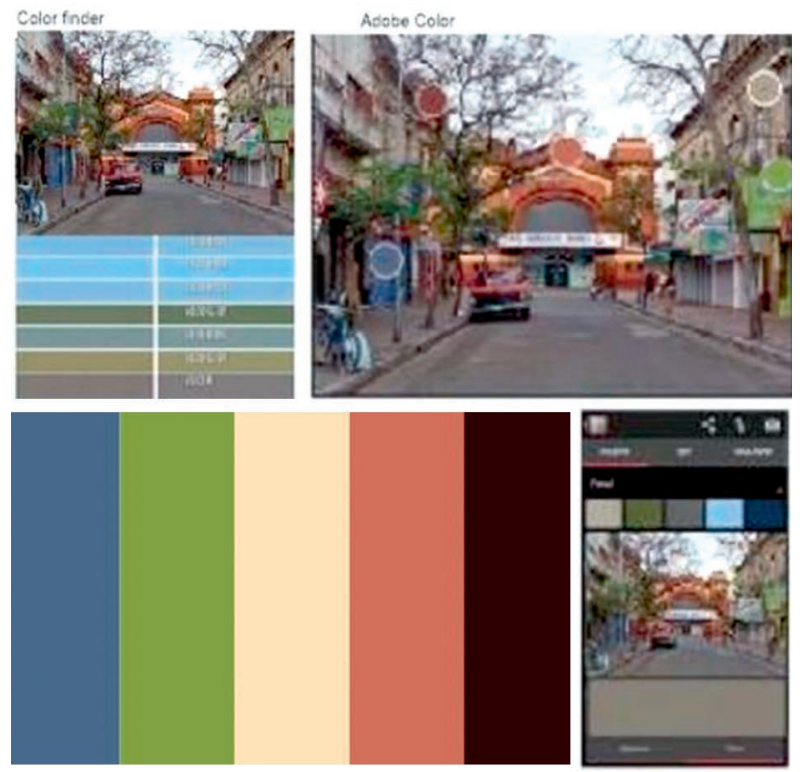

Real colors

Figura 4. Relevamiento cromático con aplicaciones digitales. Aprendizaje móvil. Fuente: autoras.

\section{Video Conceptualización del nombre - Lectura de sentido.}

En el momento de abordar el aprendizaje del proceso de ideación en arquitectura, se avanza en el procesamiento y conceptualización de la idea desde el uso de dispositivos y aplicaciones para la grabación, edición y publicación on-line de videos.

La consigna para el desarrollo del trabajo práctico fue la de explorar un nombre, provisto por la cátedra a manera de metáfora, como mecanismo disparador de procesos de ideación en la forma urbana. El nombre debía ser trabajado con registros de video para poner en común percepciones y conceptualizaciones que propusieran una nueva identidad para el sector del Mercado Norte. En esta oportunidad, los estudiantes en grupos de 6 a 8 personas eligieron un nombre, reflexionaron sobre el mismo, buscaron significados, analogías, relaciones, imágenes y conceptos claves. Adicionalmente, debieron representar y presentar en formato video las asociaciones y los significados encontrados. Por eso, cada grupo realizó una exposición oral para todos los integrantes del taller, aportando a la comprensión del nombre elegido. Para ello, se valieron de aplicaciones y programas gratuitos de edición de videos. 

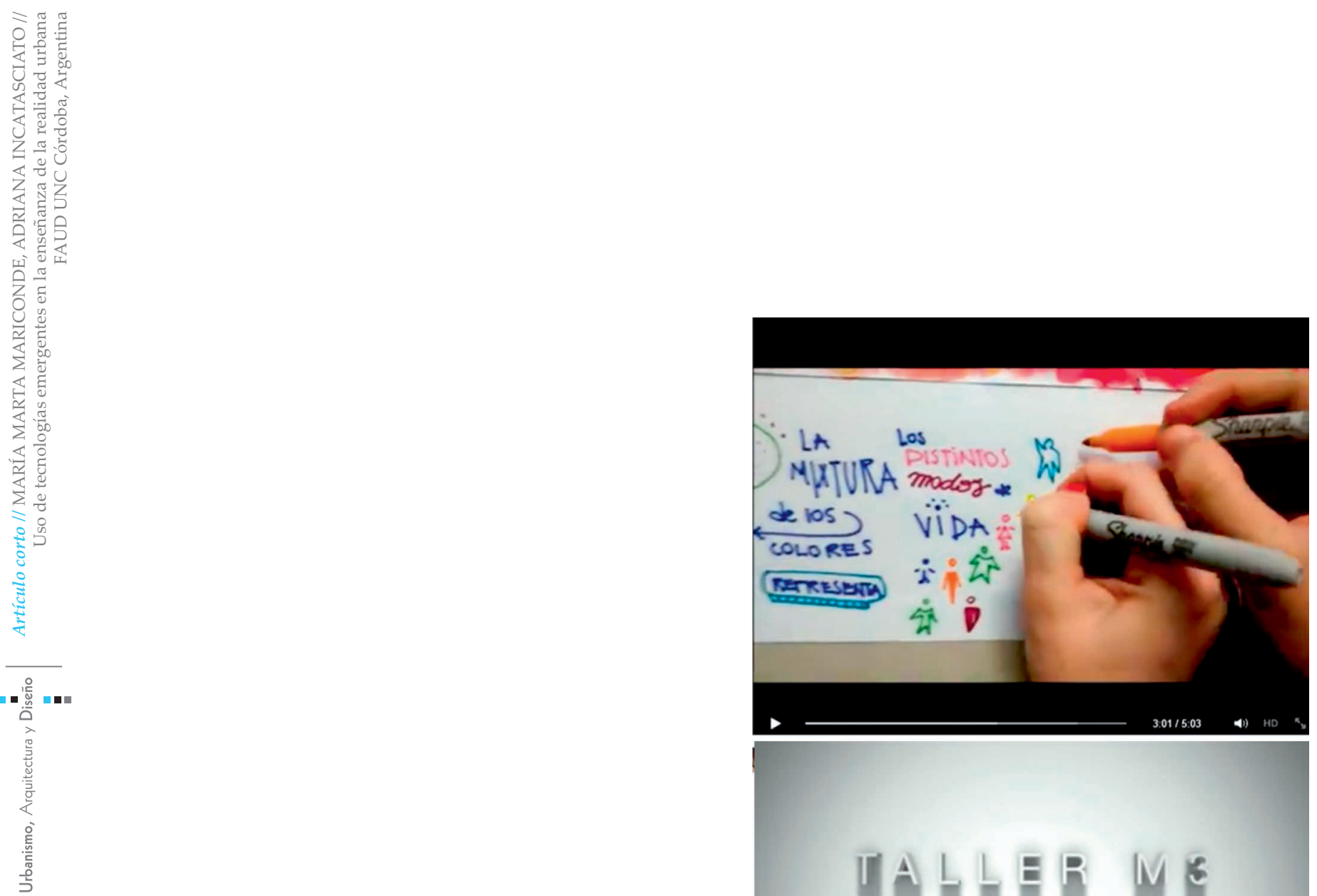

174

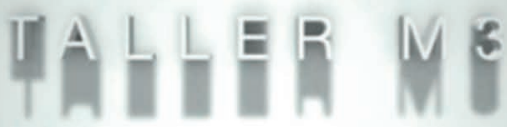

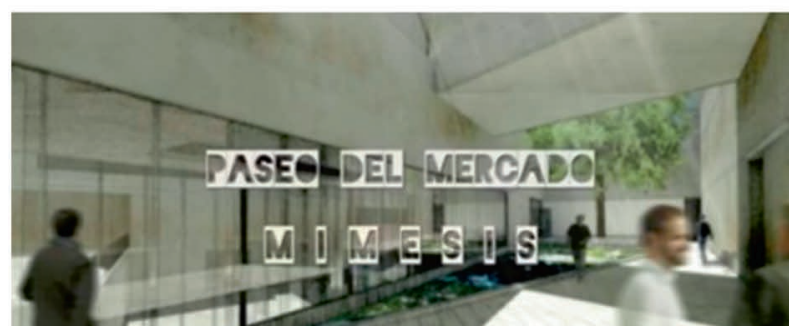

Figuras 5 y 6. Ejemplos de videos producidos por estudiantes. 


\section{Reflexiones}

A partir de las prácticas pedagógicas desarrolladas en nuestra disciplina utilizando las tecnologías emergentes, estamos en condición de afirmar que la revolución tecnológica ha impactado significativamente en nuestro rol de educadores. La diversidad de información disponible en Internet, la multitud de recursos y la posibilidad de aplicabilidad del concepto de mobile learning en el estudio del objeto arquitectónico y urbano, nos lleva al desafío de seguir innovando en la rutina de las prácticas docentes cotidianas.

Consideramos que esta experiencia de lecturas de ciudad con la incorporación de dispositivos móviles en los talleres de Morfología III, se considera motivadora y dinamizadora en los procesos de interpretación de la realidad urbana, dando la posibilidad de operar con propuestas superadoras, respaldando y reforzando los procesos de construcción colaborativa del conocimiento y, sobre todo, a la construcción de sentido en las prácticas educativas cotidianas.

Esto posibilita la aplicación concreta de los contenidos de la asignatura y permite centrar al estudiante en un contexto y tiempo reales, donde cada herramienta (dispositivos móviles con sus aplicaciones) es considerada como un instrumento con fines educativos que facilita complementar y ampliar los conocimientos.

\section{REFERENCIAS BIBLIOGRÁFICAS}

Adell, J. y Castañeda, L. (2012). Tecnologías emergentes, ¿pedagogías emergentes? En J.Hernández, M. Pennesi, D. Sobrino y A. Vázquez (coord.). Tendencias emergentes en educación con TIC (pp. 13-32). Barcelona: Asociación Espiral, Educación y Tecnología.

Reig, D. y Vilchez, L. (2013). Los jóvenes en la era de la hiperconectividad: tendencias, claves y miradas. Madrid: Fundación Telefónica.

Veletsianos, G. (2010) A definition of emerging technologies for education. En Veletsianos, G. (ed.) Emerging technologies in distance education (pp. 3-22). Athabasca, CA: Athabasca University Press E-book. 